\title{
Financial globalization and economic growth
}

\author{
Delfim Gomes Neto*
}

February 2005

\begin{abstract}
Capital mobility leads to a speed of convergence smaller in an open economy than in a closed economy. This is related to the presence of two capitals, produced with specific technologies, and where one of the capitals is nontradable, like infrastructures or human capital. Suppose, for example, that the economy is relatively less abundant in human capital, leading to a decrease of the remuneration of this capital during the transition. In a closed economy, the remuneration of physical capital will be increasing during the transition. In the open economy, the alternative investment yields the international interest rate, corresponding to the steady state net remuneration of physical capital in the closed economy. The nonarbitrage condition shows a larger difference in the remuneration of the two capitals in the closed economy. It leads to a higher accumulation of human capital and thus to a faster speed of convergence in the closed economy. This result stands in sharp contrast with that of the one-sector neoclassical growth model, where the speed of convergence is smaller in the closed economy.
\end{abstract}

\footnotetext{
*I am grateful to Gene Grossman and Gilles Saint-Paul for helpful comments and suggestions. I am also grateful to Stefano Bosi, François Bourguignon, Daniel Cohen, Pierre-Olivier Gourinchas, Clemens Grafe, Nobuhiro Kiyotaki, Philippe Martin, Thierry Verdier and Carlos Winograd for useful discussions and to conference participants of SED at New York, LAMES at São Paulo, LACEA at Madrid and EEA at Venice. I thank Fundação para a Ciência e Tecnologia for financial support. Address: Facultade de Ciencias Económicas e Empresariais, Universidade de Vigo, Campus As Lagoas-Marcosende, 36310 Vigo, Spain. Tel: +34 986 813531. Fax: +34986 812401. Email: dneto@uvigo.es
} 


\section{Introduction}

Financial openness has increased from the period 1960-1980 to the period 1980-2000. Developed countries have been opening the capital account since the mid-eighties or the beginning of the nineties. Developing countries have a clear pattern of financial opening since the beginning of the nineties or mid-nineties ${ }^{1}$. The change in the stock of capital inflows and outflows as a share of GDP of a country from 1981-1985 to 1997-2001 gives an idea of financial integration. For developed countries there is a change of $77.3 \%$ and for developing countries there is a change of $19.9 \%^{2}$. There is a growing literature on the empirical effects of financial openness on growth. In a survey of the studies on this issue, Prasad et al. (2003) conclude that there is not a robust and positive effect of international financial integration on growth.

At least for developed countries, the possibility of finding no effect of financial integration is more surprising taking into account the theory on convergence in open economies with capital mobility. Let us go back to the periods 1960-1980 and 1980-2000 and remember the moment and the intensity of financial openness for developed countries referred to above. In the Appendix Table 1, we regress the growth rate of GDP on a constant and the logarithm of the initial level of GDP. The coefficient associated with the speed of convergence is smaller for the period 1980-2000, that is the period of more financial integration. Although a detailed empirical analysis is beyond our purpose, this evidence seems to suggest an effect of financial integration on the speed of convergence that reverses the intuition associated with the one sector growth model. Could this effect make sense at a theoretical level?

\footnotetext{
${ }^{1}$ These patterns are presented in Prasad, Rogoff, Wei and Kose (2003) using two proxies for financial openness. See Figure 1 in their paper. One proxy measures restrictions on capital account and equals zero if there are no restrictions and one if there are restrictions. The data are from the IMF's Annual Report on Exchange Arrangements and Exchange Restrictions. The other proxy measures the stock of capital inflows and outflows as a share of GDP of a country. It is based on Lane and Milesi-Ferretti (2001).

${ }^{2}$ These values are taken from the World Economic Outlook, September 2002, Table 3.1.
} 
In this paper we want to analyze the effects of capital mobility in the speed of convergence. This is a much less studied issue than trade openness and the speed of convergence. We compare the speed of convergence of closed and open economies where infra-structures (we can also think of human capital) are produced with specific technology. The economy accumulates two capitals. On the one hand physical capital, and on the other hand infra-structures or human capital. In the open economy, physical capital is tradable and human capital is nontradable. Although this strategy can suggest only an increase in the complexity of the analysis, what happens is that one can understand the transitional dynamics using a non-arbitrage condition where the difference in the remuneration of both capitals gives the incentive to accumulate relatively more in one or another capital. This non-arbitrage condition provides the transitional dynamics of the model in a simple way.

Moreover, we arrive at a surprising result. The speed of convergence of the open economy is smaller than that of the closed economy. This result stands in sharp contrast with that of the one-sector neoclassical growth model, where the speed of convergence is smaller in the closed economy.

Suppose, for example, that initially an economy has relatively more physical capital than human capital. The remuneration of human capital is relatively higher than that of physical capital and there is an incentive to invest relatively more in human capital. As human capital becomes relatively more available, its relative price (the price of human capital over the price of physical capital) decreases. During the transition to the steady state the remuneration of human capital (whose production is more intensive in human capital) will be decreasing while the remuneration of physical capital will be increasing, until we arrive at the steady state investment rate. We would like to point out that the analysis would be the same if there was relatively more human capital available.

We consider a small open economy with the same structure of the closed economy. Now consumption goods and physical capital are tradable and human capital is nontradable. The convergence of the economy can be analyzed again with the non-arbitrage condition, where now the alternative to investing in 
human capital is a foreign bond yielding the international interest rate. As for the closed economy suppose that at time zero physical capital is relatively more abundant than human capital. During the transition, the remuneration of human capital will be higher than the international interest rate and the latter higher than the remuneration of physical capital. It follows that the nonarbitrage condition gives an incentive to invest relatively more in human capital, but this incentive is higher in the closed economy than in the open economy. The higher incentive in the closed economy to invest relatively more in human capital also leads to a speed of convergence faster in the closed economy than in the open economy.

Our main result, whose intuition was presented above, is at least valid for a given level of adjustment costs. With the aim of comparing exactly the same structure of production, we develop a closed economy with adjustment costs. We analytically derive its speed of convergence, when the utility function is logarithmic and the share of physical capital in the production of human capital goes in limit to zero. We show that our result applies for any finite value of the adjustment costs, in an economy with incomplete specialization.

Our paper is related to several important strands of theory on growth, convergence and openness. First there is the literature on two-sector endogenous growth models, as Lucas (1988) and Rebelo (1991). The characterization of transitional dynamics of these models is seen in Bond, Wang and Yip (1996) and Mulligan and Sala-i-Martin (1993). Ortigueira and Santos (1997) arrive at an analytical expression for the speed of convergence based on a theorem presented in the appendix of their paper. A second strand, with tradition in international economics, makes a distinction between tradable and nontradable goods. For one of the first formalization in the spirit of our model see Bruno (1976). Brock and Turnovsky (1994) characterize the dynamics of this model, but they are not interested in the speed of convergence of this open economy. Farmer and Lahiri (2002) analyze the transitional dynamics of a two countries world economy. These authors also use a two-sector endogenous growth model 
and the distinction tradables-nontradables, but they do not present analytical expressions for the speed of convergence. Turnovsky (1996) develops a dependent economy using a two-sector endogenous growth model, but he is not analyzing the speed of convergence. He is interested in the dynamics of the model following a shock in the parameters. Finally, our paper can be related to the literature on open economies and growth, which concentrates more on trade in goods. See, for example, Grossman and Helpman (1991) for the effects of trade in the incentives to innovate. Papers that also characterize the transitional dynamics are Ventura (1997) and Acemoglu and Ventura (2002). The former does not have capital mobility, based on a form of factor price equalization. In the latter there is no capital mobility by assumption and they establish a positive link between trade openness and speed of convergence. A model that assumes technological spillovers from advanced countries to backward countries and derives its transitional dynamics is presented in Howitt (2000). Obstfeld (1994) use a stochastic version of the AK model to illustrate how world capital market integration can raise steady-state growth.

The paper is organized as follows. Section 2 presents a two sector endogenous growth model and its dynamics. Section 3 develops a closed economy version with adjustment costs. In Section 4 we present a small open economy with adjustment costs. In this model the speed of convergence does not depend on the adjustment costs, for an economy with incomplete specialization in production. We will compare the speed of convergence of the open economy with the speed of a closed economy, both with adjustment costs. Concluding remarks are presented in Section 5. The Appendix contains details of the derivation of some analytical results.

\section{A two sector endogenous growth model}

This section presents the structure of a two sector endogenous growth model and derives an analytical solution for its speed of convergence. This analytical 
solution is our theoretical contribution in this Section and we also provide an intuition of the behaviour of the transitional dynamics, based on a non-arbitrage condition for the accumulation of physical and human capital. We will use this analytical solution of the speed of convergence and the intuition associated with it when comparing the speed of convergence of the closed and the open economies. Appendix A contains most of the characterization of this model, as it has been studied by Bond et al. (1996).

\subsection{The model}

The utility function of the representative agent is given by:

$$
U(C)=\frac{C^{1-\sigma}-1}{1-\sigma}
$$

where $C$ represents consumption, $\sigma>0$ is the inverse of the intertemporal elasticity of substitution. For $\sigma=1$, we have $U(C)=\log C$.

There are two sectors of production, one $\left(Y^{K}\right)$ for consumption goods and accumulation of physical capital, $\dot{K}$, and the other $\left(Y^{H}\right)$ for accumulation of human capital, $\dot{H}$. The technologies are similar to the ones in Lucas (1988), but here the production of human capital also uses physical capital ${ }^{3}$. There are no externalities.

We have

$$
\begin{aligned}
& \dot{K}=Y^{K}-\delta_{K} K-C=A(v K)^{\alpha}(u H)^{1-\alpha}-\delta_{K} K-C, \\
& \dot{H}=Y^{H}-\delta_{H} H=B[(1-v) K]^{\beta}[(1-u) H]^{1-\beta}-\delta_{H} H .
\end{aligned}
$$

The depreciation rate is $\delta_{i}$, with $i=K, H$, for physical capital and human capital, respectively. $\alpha(0<\alpha<1)$ is a parameter with $1-\alpha$ representing the share of nontradable capital in the consumption sector; $v(0 \leq v \leq 1)$ is the fraction

\footnotetext{
${ }^{3}$ For an analysis of this general model and its dynamics see Bond et al. (1996) and Mulligan and Sala-i-Martin (1993). The latter characterize the transitional dynamics giving values to the parameters of the model. The former present an analytical and geometrical solution to the dynamics of the model.
} 
of the physical capital and $u(0 \leq u \leq 1)$ is the fraction of the human capital used in the consumption sector. $A$ and $B$ represent the level of technology in the consumption and the human capital sectors, respectively, and $\beta(0<\beta<1)$ is the share of physical capital in the human capital sector.

We assume that $Y^{K}$ is more intensive in physical capital $(\alpha>\beta)^{4}$.

The planning problem is

$$
\max _{C, v, u, K, H} \int_{0}^{+\infty} \frac{C^{1-\sigma}-1}{1-\sigma} e^{-\rho t} d t
$$

subject to equations (2) and (3). $K_{0}>0$ and $H_{0}>0$ are given and $C \geq 0$. The parameter $\rho$ represents the subjective discount rate. In Appendix A.1 we present the first order conditions of the model and the characterization of its transitional dynamics. In the next subsection we derive the analytical expression of the speed of convergence and the intuition associated with it.

\subsection{The speed of convergence}

We define $P$ as the relative price of human capital in terms of goods and physical capital. That is, the relative price in this economy is given by the relative price of the two assets in the economy.

As shown in Appendix A.1, the differential equation of the relative price depends only on itself, making it possible to find a negative eigenvalue, driving the relative price to the steady state:

$$
\frac{\dot{P}}{P}=\left(r^{K}-\delta_{K}\right)-\left(\frac{1}{P} r^{H}-\delta_{H}\right)
$$

The rental rate of physical and human capital are represented, respectively, by $r^{K}$ and $r^{H}$. Assuming there is incomplete specialization in production, we show in Appendix A.1 that the rental rate of each capital is a function of the relative price: $r^{K}=\alpha A \phi^{\alpha-1} P^{\frac{\alpha-1}{\alpha-\beta}}$ and $r^{H}=(1-\alpha) A \phi^{\alpha} P^{\frac{\alpha}{\alpha-\beta}}$, where $\phi \equiv$ $\left[\frac{B}{A}\left(\frac{\beta}{\alpha}\right)^{\beta}\left(\frac{1-\alpha}{1-\beta}\right)^{\beta-1}\right]^{\frac{1}{\alpha-\beta}}$ is a constant.

\footnotetext{
${ }^{4}$ That is we assume the production of goods and physical capital is more intensive in physical capital. This leads to the stability of the differential equation of the relative price. The case where $\alpha<\beta$ is discussed in Appendix A.3.
} 
The model has a balanced growth path. As is known, in the steady state $\frac{\dot{P}}{P}=0$. Equation (5) gives the steady state value of the relative price $P^{*}$, as the rental rate of physical and human capital depends only on the relative price. Then we obtain the steady state rental rate of physical capital $\left(r^{K}\right)^{*}$ and human capital $\left(r^{H}\right)^{*}$ using equations (A8) and (A9), respectively. Notice that $P^{*},\left(r^{K}\right)^{*}$ and $\left(r^{H}\right)^{*}$ only depend on technological parameters ${ }^{5}$.

Linearizing the system around the steady state gives the following equation to the relative price:

$$
\dot{P}=a_{33}\left(P-P^{*}\right)
$$

where $a_{33}$ represents the partial derivative of the equation (5) with respect to $P$, at the steady state values. These derivations are in Appendix A.2.

All other variables of the system converge to the steady state following the saddle-path. Given the assumptions stated above, the dynamics of the system and its speed of convergence can be given by the coefficient $a_{33}$ of the equation of the relative price:

$$
a_{33}=-\frac{[(1-\alpha)+\beta]\left(r^{K}\right)^{*}+\beta\left(\delta_{H}-\delta_{K}\right)}{\alpha-\beta} .
$$

By $a_{33}$, we can see that (for a given ratio physical capital-human capital, $k$ ) an increase in the relative price, $P$, leads to an increase in the remuneration of the human capital, the factor used intensively in the production of human capital $(\alpha>\beta)$ and the latter expression is negative. This is in relation to the Stolper-Samuelson theorem. It follows that the relative price has a stabilizing effect in the transitional dynamics of the economy. On the other hand, the capital ratio has a destabilizing role. In Appendix A.2 we show that $a_{22}=$ $\left(\frac{\partial y^{K}}{\partial k}-\frac{\partial y^{H}}{\partial k}\right) k^{*}>0$. By $a_{22}$, we can see that (for a given relative price) an increase in the ratio physical capital-human capital, $k$, leads to an increase in the output of the consumption sector and a decrease in the output of the human capital sector and this expression is positive. This is in relation to the Rybczynski theorem.

\footnotetext{
${ }^{5}$ The steady state growth rate is equal to $g=\frac{1}{\sigma}\left[\left(r^{K}\right)^{*}-\delta_{K}-\rho\right]>0$. See Appendix A.1.
} 
For simplicity of the analysis, we assume $\delta_{K}=\delta_{H}$. The speed of convergence is given $b y^{6}$

$$
\lambda_{C}=\frac{(1-\alpha)+\beta}{\alpha-\beta}\left(r^{K}\right)^{*}
$$

where $\left(r^{K}\right)^{*}$ is the value of the marginal productivity of capital in the steady state. This value depends only on technological parameters, as we can see looking at the differential equation of the relative price, leaving no role for the parameter of preferences. The speed of convergence increases with $\beta$ and decreases with $\alpha$. As the share of human capital in the production of human capital decreases $(1-\beta)$, decreasing returns of human capital in this sector set in faster. The same argument applies to $\alpha$ and decreasing returns of physical capital in the production sector of consumption goods and physical capital.

We can analyze the transitional dynamics of the system by taking into account the behavior of the relative price and the remuneration of the two capitals, as given by the non-arbitrage condition given by equation (5). Investing one unit of physical capital yields a net marginal product of physical capital in the consumption goods equal to $r^{K}-\delta_{K}$. On the other hand, investing $\frac{1}{P}$ units of human capital yields $\frac{\dot{P}}{P}+\frac{1}{P} r^{H}-\delta_{H}$. In the steady state, $\left(r^{K}\right)^{*}=\left(\frac{1}{P} r^{H}\right)^{*}=r^{*}+\delta_{K}$, with $\delta_{K}=\delta_{H}$. We will call $r^{*}$ the steady state interest rate. The speed of convergence and the transitional path apply to any situation around the steady state: $k_{0} \neq k^{*}$. By assuming for example that $k_{0}>k^{*}$, human capital is relatively less abundant and its remuneration will be relatively higher than physical capital: $\frac{1}{P} r^{H}>r^{K}$. Notice that there will be an incentive to invest relatively more in human capital. As $\alpha>\beta$ and the

\footnotetext{
${ }^{6}$ The papers referred to above, Bond et al. (1996) and Mulligan and Sala-i-Martin (1993), do not arrive at an expression for the speed of convergence. Using the Lucas (1988) model, Ortigueira and Santos (1997) present an expression for the speed of convergence, but the analytical solution is derived in the appendix of their paper. These authors also analyze the behaviour of the speed of convergence of the non-linearized model and they show that the linearized model represents well the behaviour of the transitional dynamics over substantial phases of the transition. Working with the linearized version of the transitional dynamics, our results are all derived analytically.
} 
remunerations of the two capitals depend only on the relative price, taking into account equations (A9) and (A8), $\frac{1}{P} r^{H}$ will be decreasing and $r^{K}$ will be increasing during the transition to the steady state. As human capital becomes relatively more available, the relative price will be decreasing.

Look at Appendix A.3 the case where $\alpha<\beta$.

We will return to these expressions of the speed of convergence when comparing the closed and open economies. The next Section will discuss the presence of adjustment costs in the closed economy and its effect in the speed of convergence.

\section{The closed economy}

Based on the model of the previous Section, now we introduce adjustment costs in the closed economy. Later we will compare this economy with an open economy using also adjustment costs.

\subsection{The model}

The planning problem is now

$$
\max _{C, v, u, I^{T}, K, H} \int_{0}^{+\infty} \frac{C^{1-\sigma}-1}{1-\sigma} e^{-\rho t} d t
$$

subject to

$$
\begin{gathered}
A(v K)^{\alpha}(u H)^{1-\alpha}=C+I^{T}\left[1+m\left(\frac{I^{T}}{K}\right)\right] \\
\dot{K}=I^{T}-\delta_{K} K \\
\dot{H}=B[(1-v) K]^{\beta}[(1-u) H]^{1-\beta}-\delta_{H} H
\end{gathered}
$$

with $K_{0}$ and $H_{0}$ given. Equations (8a) and (8b) appear in the place of equation

(2) of the model presented in Section 2. The expression of the adjustment costs, 
$m\left(\frac{I^{T}}{K}\right)$, can be represented in the following way ${ }^{7}$ :

$$
m\left(\frac{I^{T}}{K}\right)=\frac{\frac{h}{2}\left(\frac{I^{T}}{K}-a\right)^{2}}{\frac{I^{T}}{K}} .
$$

The parameter $h$ is the sensitivity of the adjustment costs to the ratio investment to physical capital. The steady state value of the Tobin's $q$ will be $q^{*}=1$ if we assume $a=g+\delta_{K}$, where $g$ represents the steady state growth rate of the closed economy. This growth rate is equal to the steady state growth rate of the model of Section 2 and will also be equal to the steady state growth rate of the open economy. As we are using the same economic structure and all relevant variables have the same steady state values in both economies, we guarantee the comparability between the closed and the open economies.

The Hamiltonian for this problem is

$$
\begin{aligned}
J & =U(C) e^{-\rho t}+\eta e^{-\rho t}\left\{A(v K)^{\alpha}(u H)^{1-\alpha}-C-I^{T}\left[1+m\left(\frac{I^{T}}{K}\right)\right]\right\}+ \\
& +\eta q e^{-\rho t}\left(I^{T}-\delta_{K} K\right)+\mu e^{-\rho t}\left\{B[(1-v) K]^{\beta}[(1-u) H]^{1-\beta}-\delta_{H} H\right\}
\end{aligned}
$$

where $\eta$ is the Lagrangian multiplier associated with equation (8a), $\eta q$ is the costate variable in installed physical capital ${ }^{8}$ and $\mu$ is the costate variable in human capital.

In addition to equations (A1) to (A4) presented in Appendix A.1, we obtain the following first order conditions ${ }^{9}$ :

$$
\begin{gathered}
q=1+h\left(\frac{I^{T}}{K}-a\right) \\
\dot{q}=\left(\rho+\delta_{K}-\frac{\dot{\eta}}{\eta}\right) q-r^{K}-h\left(\frac{I^{T}}{K}-a\right) \frac{I^{T}}{K}+\frac{h}{2}\left(\frac{I^{T}}{K}-a\right)^{2} .
\end{gathered}
$$

\footnotetext{
${ }^{7}$ For this specification of adjustment costs see Ortigueira and Santos (1997), King and Rebelo (1993) and Summers (1981).

${ }^{8}$ Defining this costate variable as $\eta q e^{-\lambda t}$ rather than as a single variable is a matter of convenience, as it will become clear later on when we show that $q$ plays a key role in determining investment.

${ }^{9}$ We would like to point out that other properties of the model of Section 2, derived in Appendix A.1, apply in the closed economy with adjustment costs.
} 
The transversality conditions are:

$$
\lim _{t \rightarrow+\infty} \eta q e^{-\rho t} K=0 \text { and } \lim _{t \rightarrow+\infty} \mu e^{-\rho t} H=0 .
$$

We can define $P=\frac{\mu}{\eta}$ as the relative price of human capital in terms of goods. Notice that we will be using now the marginal utility of consumption, as $\eta=C^{-\sigma}=U^{\prime}(C)$. It follows that $\frac{\dot{P}}{P}=\frac{\dot{\mu}}{\mu}-\frac{\dot{\eta}}{\eta}=\frac{\dot{\mu}}{\mu}+\sigma \frac{\dot{C}}{C}$.

The dynamic system is now given by:

$$
\begin{gathered}
\frac{\dot{c}}{c}=\frac{\dot{C}}{C}-\left(\frac{q-1}{h}+g\right) \\
\frac{\dot{k}}{k}=\left(\frac{q-1}{h}+g\right)-\left(y^{H}-\delta_{H}\right) \\
\dot{q}=\left(\rho+\delta_{K}+\sigma \frac{\dot{C}}{C}\right) q-r^{K}-(q-1) a-\frac{h}{2}\left(\frac{q-1}{h}\right)^{2} \\
\frac{\dot{P}}{P}=\left(\rho+\delta_{H}-\frac{r^{H}}{P}\right)+\sigma \frac{\dot{C}}{C}
\end{gathered}
$$

and it takes into account the transversality conditions for $K$ and $H$.

The specificity of this model is that one needs to solve equation (11a). By using equation (8a) and the definition $c=\frac{C}{K}$, we have

$$
c=y^{K}-\left(\frac{q-1}{h}+a\right)-\frac{h}{2}\left(\frac{q-1}{h}\right)^{2}
$$

and then $c$ depends also on $k, q$ and $P$. We can also specify equation (11a) as a function of the same variables. It follows that the differential equations of $q$ and $P$ will be also a function of the same variables. Notice that

$$
\frac{\dot{c}}{c}=\frac{\left(\dot{y}^{K}-\frac{q}{h} \dot{q}\right)}{c}
$$

and using equations (A12), (A8) and (A9) presented in Appendix A.1

$$
\dot{y}^{K}=\frac{1}{\alpha-\beta}\left[(1-\beta) \frac{\alpha-1}{\alpha-\beta} r^{K} \frac{\dot{P}}{P}-\frac{\beta}{k} \frac{\alpha}{\alpha-\beta} r^{H} \frac{\dot{P}}{P}+\frac{\beta}{k} r^{H} \frac{\dot{k}}{k}\right] .
$$

In this general form, the linearized system has three equations depending on three variables. With such a system, it is not possible to find a clear analytical 
solution for the dynamics of the economy. One expects that increasing the adjustment costs will decrease the speed of convergence, as in the Solow model with adjustment $\operatorname{costs}^{10}$. By assuming that human capital is produced only with human capital, Ortigueira and Santos (1997) make simulations of the speed of convergence for a closed economy with endogenous growth and adjustment costs for physical capital and find that increasing the adjustment costs decreases the speed of convergence.

We will look now for conditions that give the possibility of finding an analytical solution for the speed of convergence of this model.

\subsection{The transitional dynamics and the speed of conver- gence}

We can reduce the system to two differential equations on $q$ and $P$, analyzing the case where human capital is produced only with human capital $(\beta \rightarrow 0)$. This implies:

$$
\dot{y}^{K}=\frac{1}{\alpha} \frac{\alpha-1}{\alpha} r^{K} \frac{\dot{P}}{P} .
$$

In this case the production of tradable goods over physical capital and consumption over physical capital depend only on $q$ and $P$. Then we can analyze the dynamics of the system with the differential equations of Tobin's $q$ and of the relative price $P$. With $\beta \rightarrow 0$, it follows that $r^{H}=P B$, implying that $\left(r^{K}\right)^{*}=B=\left(\frac{r^{H}}{P}\right)^{*}$. Remember that we have assumed $\delta_{K}=\delta_{H}$.

The system is now:

$$
\begin{gathered}
\dot{q}=\left(\rho+\delta_{K}+\sigma \frac{\dot{C}}{C}\right) q-r^{K}-(q-1) a-\frac{h}{2}\left(\frac{q-1}{h}\right)^{2} \\
\frac{\dot{P}}{P}=\left(\rho+\delta_{H}-B\right)+\sigma \frac{\dot{C}}{C}
\end{gathered}
$$

\footnotetext{
${ }^{10}$ For the one sector model, we can derive an explicit solution for the speed of convergence of the linearized system. Abel and Blanchard (1983) characterize geometrically the dynamics of the one sector model with adjustment costs.
} 
where

$$
\frac{\dot{C}}{C}=\left(\frac{q-1}{h}+g\right)+\frac{1}{c}\left(\frac{1}{\alpha} \frac{\alpha-1}{\alpha} r^{K} \frac{\dot{P}}{P}-\frac{q}{h} \dot{q}\right) .
$$

By using equations (13) and (15) we have (18).

By assuming that $\sigma=1$ and $\delta_{K}=\delta_{H}=0$, we have an analytical solution for the speed of convergence of this model and we can observe its behavior when changing the parameter of adjustment costs. We derive the negative eigenvalue of this system in Appendix B.

Let $\lambda_{C(h)}=-\mu$ be the speed of convergence of this closed economy with adjustment costs:

$$
2 \lambda_{C(h)}=-\rho+\left[\rho^{2}+4 \frac{1-\alpha}{\alpha} B \Delta\right]^{\frac{1}{2}}
$$

where

$$
\Delta=\frac{1}{h} A_{P}^{*} A_{q}^{*}=\frac{1}{h\left(1+\frac{1}{c^{*}} \frac{1}{\alpha} \frac{1-\alpha}{\alpha} B\right)+\frac{1}{c^{*}}} .
$$

In Appendix $B$ we show that the speed of convergence of this closed economy is decreasing in the adjustment costs, that is $\frac{\partial \lambda_{C(h)}}{\partial h}<0$.

One would expect the speed of convergence of this economy to approach the speed of convergence of the closed economy presented in Section 2 when the adjustment costs go to zero (see equation (6) with $\beta=\delta_{K}=\delta_{H}=0$ ). In fact:

$\lim _{h \rightarrow 0} \lambda_{C(h)}=\frac{1-\alpha}{\alpha} B$, corresponding to the speed of convergence of the same model of a closed economy without adjustment costs. That is $\lambda_{C}=\lambda_{C(h=0)}$.

It is also interesting to know what happens if the adjustment costs go to infinite. We have

$$
\lim _{h \rightarrow \infty} \lambda_{C(h)}=0 .
$$

We would like to point out one conclusion that will be used later on when comparing the speed of convergence of the closed and the open economies. Since the adjustment costs have a finite value, the speed of convergence of the closed economy is always greater than zero. 


\section{The open economy to capital mobility}

First we want to point out that openness in this Section means access to international capital markets. We are not analyzing trade effects on growth and convergence.

We have seen that a two sector growth model for a closed economy presents a finite speed of convergence. Notwithstanding, the two sector open economy growth model based on the model of Section 2 does not have a finite speed of convergence, because the international interest rate ties down the marginal productivity of capital and, in this way, also determines the steady state relative price. Thus, the stabilizing mechanism provided in the closed economy by the relative price when $\alpha>\beta$ is eliminated. Then the economy would jump immediately to the steady state ${ }^{11}$. We would like to point out that this situation happens because we are using only two factors of production ${ }^{12}$.

We develop an open economy model where physical capital and consumption will be tradable goods and human capital will be assumed nontradable. To avoid the problem of instantaneous adjustment, we will introduce adjustment costs in

\footnotetext{
${ }^{11}$ The Solow model predicts a finite speed of convergence for a closed economy. But a small open economy with the same characteristics would have an infinite speed of convergence. With perfect international capital mobility, the remuneration of capital in a small open economy must be equal to the international interest rate and capital flows would eliminate any difference in remunerations instantaneously. Even allowing for adjustment costs in the small open economy, the closed economy with the same structure has a smaller speed of convergence. Credit constraints can be introduced in an economy using physical and human capital in production, where only physical capital can be used as collateral for foreign borrowing. The previous conclusion does not change and the values of the speed of convergence in the model may be closer to the values one finds in the empirical literature. For a discussion on convergence of open economies see Barro and Sala-i-Martin (1995), chapter 3, and Obstfeld and Rogoff (1996), chapter 7 .

${ }^{12}$ In a two-sector open economy exogenous growth model using physical capital, human capital and labor as input, one does not need to introduce adjustment costs for having transitional dynamics. Brock and Turnovsky (1994) develop a model with these elements and characterize its dynamics, but they were not looking for the speed of convergence of this open economy.
} 
the accumulation of physical capital, as in the closed economy presented in Section 3. As the remuneration of physical capital is not restricted to be equal to the international interest rate during the transition, the stable mechanism of the relative price will be again at work as in Section 2.

Surprisingly, we show that the speed of convergence of the open economy is smaller than the speed of convergence of the closed economy. We will see that an economy with incomplete specialization in production has a speed of convergence that does not depend on the adjustment costs. The speed of convergence also does not depend on the parameter of preferences in this open economy with adjustment costs.

These results are in contrast with the dynamics of the one sector open economy with adjustment costs.

\subsection{The model}

The planning problem is now

$$
\max _{C, v, u, I^{T}, K, H, B} \int_{0}^{+\infty} \frac{C^{1-\sigma}-1}{1-\sigma} e^{-\rho t} d t
$$

subject to

$$
\begin{gathered}
\dot{D}=r^{*} D+A(v K)^{\alpha}(u H)^{1-\alpha}-C-I^{T}\left[1+m\left(\frac{I^{T}}{K}\right)\right] \\
\dot{K}=I^{T}-\delta_{K} K \\
\dot{H}=B[(1-v) K]^{\beta}[(1-u) H]^{1-\beta}-\delta_{H} H
\end{gathered}
$$

with $D_{0}, K_{0}$ and $H_{0}$ given.

Let $D$ represent net foreign bonds accumulated by the economy and $r^{*}$ be the international interest rate. Notice that equation (21a) replaces equation (8a) of the closed economy. The expression of the adjustment costs in equation (21a) is equal to the expression in equation (9) presented in the closed economy with adjustment costs. We are assuming that $r^{*}$ is equal to $\left(r^{K}\right)^{*}-\delta_{K}$, as determined in the steady state of the closed economy. This implies that the 
closed and the open economy have the same production structure, as stated above, and that we are assuming the rest of the world is in the steady state.

The Hamiltonian for this problem is now

$$
\begin{aligned}
J & =U(C) e^{-\rho t}+\eta e^{-\rho t}\left\{r^{*} D+A(v K)^{\alpha}(u H)^{1-\alpha}-C-I^{T}\left[1+m\left(\frac{I^{T}}{K}\right)\right]\right\}+ \\
& +\eta q e^{-\rho t}\left(I^{T}-\delta_{K} K\right)+\mu e^{-\rho t}\left\{B[(1-v) K]^{\beta}[(1-u) H]^{1-\beta}-\delta_{H} H\right\}
\end{aligned}
$$

where $\eta, \eta q$ and $\mu$ are the costate variables in net foreign bonds, installed physical capital and human capital, respectively.

In addition to equations (A1) to (A4) presented in Appendix A.1, we obtain the following first order conditions ${ }^{13}$ :

$$
\begin{gathered}
q=1+h\left(\frac{I^{T}}{K}-a\right) \\
\dot{\eta}=\eta\left(\rho-r^{*}\right) \\
\dot{q}=\left(r^{*}+\delta_{K}\right) q-r^{K}-h\left(\frac{I^{T}}{K}-a\right) \frac{I^{T}}{K}+\frac{h}{2}\left(\frac{I^{T}}{K}-a\right)^{2} .
\end{gathered}
$$

The transversality conditions are now:

$$
\lim _{t \rightarrow+\infty} \eta q e^{-\rho t} K=0, \quad \lim _{t \rightarrow+\infty} \mu e^{-\rho t} H=0 \text { and } \lim _{t \rightarrow+\infty} \eta e^{-\rho t} B=0 .
$$

Equation (22a) can be specified as

$$
\frac{q-1}{h}+g=\frac{I^{T}}{K}-\delta_{K}=\frac{\dot{K}}{K} .
$$

As in the closed economy we have $P=\frac{\mu}{\eta}$, giving the relative price of human capital in terms of goods. In this open economy $P$ is also the relative price of tradables over nontradables, that is a real exchange rate. As stated above, $\eta$ is the value of foreign bonds. Remember that the costate variable of installed physical capital in the open economy is $\eta q$, because of the adjustment costs as in the closed economy.

\footnotetext{
${ }^{13}$ As for the closed economy with adjustment costs, the properties of the model of Section 2 also apply in the open economy.
} 
The dynamic system of this open economy is given by the following equations:

$$
\begin{gathered}
\frac{\dot{c}}{c}=\frac{1}{\sigma}\left(r^{*}-\rho\right)-\left(\frac{q-1}{h}+g\right) \\
\dot{d}=\left[r^{*}-\left(\frac{q-1}{h}+g\right)\right] d+y^{K}-c-\left(\frac{q-1}{h}+a\right)-\frac{h}{2}\left(\frac{q-1}{h}\right)^{2} \\
\frac{\dot{k}}{k}=\left(\frac{q-1}{h}+g\right)-\left(y^{H}-\delta_{H}\right) \\
\dot{q}=\left(r^{*}+\delta_{K}\right) q-r^{K}-(q-1) a-\frac{h}{2}\left(\frac{q-1}{h}\right)^{2} \\
\frac{\dot{P}}{P}=r^{*}-\left(\frac{r^{H}}{P}-\delta_{H}\right)
\end{gathered}
$$

and it takes into account the transversality conditions for $D, K$ and $H$. We are representing $d=\frac{D}{K}$, implying $\frac{\dot{d}}{d}=\frac{\dot{D}}{D}-\frac{\dot{K}}{K}$.

The steady state value of the relative price is given by equation (24e). Note that $q^{*}=1$. With equation (24c) we have $k^{*}$. As we will see below, $d^{*}$ and $c^{*}$ depend on the initial conditions.

From the flow budget constraint, equation (21a), and by taking into account a no-Ponzi-game condition, we obtain the intertemporal budget constraint:

$$
\int_{0}^{+\infty} C e^{-r^{*} t}=\int_{0}^{+\infty}\left\{A(v K)^{\alpha}(u H)^{1-\alpha}-I^{T}\left[1+m\left(\frac{I^{T}}{K}\right)\right]\right\} e^{-r^{*} t}+D_{0}
$$

where $C_{t}=C_{0} e^{\frac{1}{\sigma}\left(r^{*}-\rho\right) t}$.

\subsection{The transitional dynamics and the speed of conver- gence}

Consider now the equations of $k, q$ and $P$. The linearized system of these three equations is given by

$$
\left[\begin{array}{l}
\dot{k} \\
\dot{q} \\
\dot{P}
\end{array}\right]=\left[\begin{array}{lll}
a_{11} & a_{12} & a_{13} \\
0 & a_{22} & a_{23} \\
0 & 0 & a_{33}
\end{array}\right] *\left[\begin{array}{l}
k-k^{*} \\
q-1 \\
P-P^{*}
\end{array}\right]
$$


where $a_{i j}$ represents the partial derivative of the equation $i$ with respect to the argument $j$, at the steady state values.

As in the closed economy, we consider the case where the share of physical capital in the tradable sector is greater than in the nontradable sector: $\alpha>\beta$. As the differential equation of the relative price is stable in this case, this condition leads to the stability and the dynamics of transition of the real exchange rate. Then ${ }^{14}$ :

$$
a_{11}=-\frac{\partial y^{H}}{\partial k} k^{*}>0 ; a_{22}=r^{*}-g \text { and } a_{33}=-\frac{\beta}{\alpha-\beta}\left(r^{K}\right)^{*}<0 .
$$

The other coefficients are: $a_{12}=\frac{k^{*}}{h} ; a_{13}=-\frac{\partial y^{H}}{\partial P} k^{*}>0 ; a_{23}=-\frac{\partial r^{K}}{\partial P}>0$.

Taking into account the discussion presented in Section 2, we see the coefficients $a_{11}$ and $a_{33}$ are related to the Rybczynski theorem and to the StolperSamuelson theorem, respectively. It also follows that the relative price has a stabilizing effect and the capital ratio a destabilizing role, in the transition dynamics of the economy.

The speed of convergence of this open economy, $\lambda_{O}$, is again determined with the differential equation of the relative price. Given the negative eigenvalue $a_{33}$, the expression of the speed of convergence is equal to

$$
\lambda_{O}=\frac{\beta}{\alpha-\beta}\left(r^{K}\right)^{*} .
$$

We want to point out that the speed of convergence of the open economy model does not depend on the adjustment costs. Since the economy is incompletely specialized, this result applies. This result stands in stark contrast with the small open economy neoclassical growth model with adjustment costs. The result is related to the fact that physical capital and human capital are complementary in both sectors of production and to the production of human capital being more intensive in human capital, the nontradable capital ${ }^{15}$.

\footnotetext{
${ }^{14}$ In $a_{33}$ we are assuming, as in the closed economy, that $\delta_{K}=\delta_{H}$.

${ }^{15}$ In Barro, Mankiw and Sala-i-Martin (1995) there is only one sector of production, where physical capital and human capital are complementary, but human capital cannot be used as
} 
Now we can check if the implied value of the speed of convergence is broadly consistent with the estimated values of the empirical literature on convergence. By following the equation (25), we need estimates of the share of physical capital in the production of tradable goods $\alpha$, the share of physical capital in the production of nontradable goods $\beta$, the rate of depreciation $\delta$ and the international interest rate $r^{*}$. We use the baseline values of parameters suggested by Barro and Sala-i-Martin (1995) $\left(r^{*}=0.06, \delta=0.05, \alpha=0.5 \text { and } \beta=0.1\right)^{16}$. The model implies $\lambda_{O}=0.0275$, a value in the interval of $2-3 \%$ suggested by the empirical literature.

Finally, we present the dynamics of foreign bonds. The details of the solution of equation (24b), linearized around the steady state, are in Appendix C. We have then

$$
\left(d-d^{*}\right)=\frac{\Lambda}{-\lambda_{O}-\left(r^{*}-g\right)}\left(k_{0}-k^{*}\right) e^{-\lambda_{O} t} .
$$

where the signs of the expressions in $\Lambda$ are: $y_{P}^{K}<0 ; y_{k}^{K}>0 ; \Pi>0 ; \Gamma<0$. It follows that the ambiguity of the sign of $\Lambda$ comes from $y_{P}^{K}$ being negative, as all other expressions are positive.

The ratio net foreign bonds over physical capital, $d$, is driven by the capital ratio, $k$. Because of the ambiguity of the sign of $\Lambda$, we have an ambiguity with the evolution of $d$. This ambiguity would disappear in the case $\alpha<\beta$, where the relative price has no transitional dynamics and the only term in $\Lambda$ is $y_{k}^{K}<0$.

Notice that we know $d^{*}$ with this last equation, given $t=0$ and a $k_{0}$. Then one obtains $c^{*}$ with equation (24b).

\footnotetext{
collateral for foreign borrowing and then must be accumulated in the country. Notice that in Brock and Turnovsky (1994), a two-sector neoclassical growth model, there is no collateral nor adjustment costs.

${ }^{16}$ Most of this literature uses the Lucas (1988) model where $\beta=0$. In the general model Barro and Sala-i-Martin (1995) use $\beta<0.4$.
} 


\subsection{Comparing the speed of convergence of the closed and the open economies}

This discussion on the speed of convergence proceeds in two steps. First, we assume small adjustment costs such that the closed economy can be represented by the structure without adjustment costs. In this case, we have shown that our closed economy approaches the model presented in Section 2. The intuition for the difference between the two speeds of convergence is presented. We also consider the case where $a<\beta$. Secondly, we discuss the case with positive adjustment costs in both economies.

The speed of convergence of the open economy is smaller than the speed of convergence of the closed economy presented in Section 2. This main result of the paper can be clearly read in the expressions of the speed of convergence of the closed and the open economy, $\lambda_{C}$ and $\lambda_{O}$, given by equations (6) and (25) respectively. The difference is the expression $(1-\alpha)$ in $\lambda_{C}$. As far as $0<\alpha<1$, the remuneration of physical capital will be changing during the transitional path in the closed economy. In these conditions, the gap between remunerations will be bigger in the closed economy than in the open economy. Only if $\alpha=1$ would this effect disappear, as $(1-\alpha)=0$. By equation (A2), the remuneration of physical capital would be $r^{K}=\alpha A$.

We develop now some intuition on the transitional dynamics of the relative prices in the open economy. As in Section 2 with equation (5), relevant information is provided by equation (24e). The relative incentive to accumulate one or another capital depends on their remuneration. Consider again the case $k_{0}>k^{* 17}$. Human capital is relatively less abundant and its remuneration will be relatively higher than physical capital: $\frac{1}{P} r^{H}>r^{*}$. Notice that now there is an alternative of investment given by the international interest rate $r^{*}$. This interest rate is fixed during the transition, instead of changing like the remuneration of physical capital in the closed economy where $r^{K}<r^{*}$. This differentiated pattern in the closed and the open economies leads to a gap between remuner-

\footnotetext{
${ }^{17}$ The conclusions do not change if we consider instead the case $k_{0}<k^{*}$.
} 
ations which is smaller in the open economy. It follows that the incentive to invest relatively more in human capital is bigger in the closed economy and this economy will be going faster to the steady state than the open economy. In this economy with two capitals produced with specific technologies, the speed of convergence is smaller in the open economy than in the closed economy.

Let assume $\alpha<\beta$. With the production of goods being more intensive in human capital, it follows that the negative eigenvalue would be given by $a_{11}=$ $-\frac{\partial y^{H}}{\partial k} k^{*}$. The parameter of preferences does not have influence on the speed of convergence, although we are considering an open economy with adjustment costs. These conclusions are the opposite of what we find using an open economy with one sector and adjustment costs. By taking into account the corresponding expression for the closed economy, as presented in Appendix A.3, the speed of convergence is also smaller in the open economy than in the closed economy. With $\alpha<\beta$, we have $\lambda_{O}=\frac{\partial y^{H}}{\partial k} k^{*}$ and $\lambda_{C}=\frac{\partial y^{H}}{\partial k} k^{*}(1+\xi)$, where $\xi>0$.

Now we compare the speed of convergence in the closed and the open economies, both with adjustment costs. We would like to point out that the intuition of our main result was derived above in an environment where there are adjustment costs in the open economy, but these adjustment costs were not present in the closed economy of Section 2. At least for some measure of adjustment costs in the closed economy the result presented is applicable.

As stated previously, we want to keep all the results derived analytically. We have shown in Section 3 that the speed of convergence of the closed economy with adjustment costs could be derived analytically if $\beta \rightarrow 0$. This is the case of human capital being produced only with human capital, as in Lucas (1988). It follows that we have a special case in the open economy, as its speed of convergence will go to zero (see equation (25) with $\beta \rightarrow 0$ and $\delta_{K}=\delta_{H}=0$ ). In this case, with $\beta \rightarrow 0$ and taking into account equation (19), the speed of convergence of the closed economy is always higher than the speed of convergence of the open economy.

After providing the intuition of the main result of the paper in the first step 
of this discussion, we have shown above that our main conclusion applies using two economies (closed and open) with adjustment costs. The results for the speed of convergence of closed and open economies with two capitals produced with specific technologies are opposite to the results of the one sector growth model.

\section{Conclusion}

We developed an endogenous growth model with physical capital and human capital to compare the speed of convergence of open and closed economies. As human capital was nontradable in the open economy, partial capital mobility was the only difference between these two economies. It was possible to analyze the transitional dynamics of the model with a non-arbitrage condition. The difference between remuneration of the capitals gives the incentive to accumulate relatively more in one of the capitals and this condition only depends on the relative price. The main implication of the model was a speed of convergence smaller for the open economy, a result in sharp contrast with the one sector growth model.

In terms of policy implications, our study suggests more reflection on the idea that capital mobility will increase the convergence of economies to their steady state. Given the implication of the model it would be of interest to analyze empirically these issues. The empirical literature, although looking for alternative specifications and proxies that capture a robust effect of financial openness on growth, has not analyzed in a systematic way the effects of capital mobility on the speed of convergence. The evidence referred to in the introduction suggests that the basic implication of our model may have a relation with cross-country growth patterns. Further empirical studies on this issue seems to be an interesting topic for future research. 


\section{Appendix A Derivations for the model of Sec-}

\section{tion 2}

In this Appendix we provide derivations for Section 2.

\section{A.1 First order conditions}

The Hamiltonian for the problem in Section 2 is given by

$$
\begin{aligned}
J & =U(C) e^{-\rho t}+\eta e^{-\rho t}\left[A(v K)^{\alpha}(u H)^{1-\alpha}-\delta_{K} K-C\right]+ \\
& +\mu e^{-\rho t}\left\{B[(1-v) K]^{\beta}[(1-u) H]^{1-\beta}-\delta_{H} H\right\}
\end{aligned}
$$

where $\eta$ and $\mu$ are the costate variables for physical and human capital, respectively.

We obtain the following first order conditions:

$$
\begin{gathered}
C^{-\sigma}=\eta \\
r^{K}=\alpha A(v K)^{\alpha-1}(u H)^{1-\alpha}=\frac{\mu}{\eta} \beta B[(1-v) K]^{\beta-1}[(1-u) H]^{1-\beta} \\
r^{H}=(1-\alpha) A(v K)^{\alpha}(u H)^{-\alpha}=\frac{\mu}{\eta}(1-\beta) B[(1-v) K]^{\beta}[(1-u) H]^{-\beta} \\
\dot{\mu}=\mu\left(\rho+\delta_{H}-\frac{\eta}{\mu} r^{H}\right) \\
\dot{\eta}=\eta\left(\rho+\delta_{K}-r^{K}\right)
\end{gathered}
$$

The transversality conditions are:

$$
\lim _{t \rightarrow+\infty} \eta e^{-\rho t} K=0 \text { and } \lim _{t \rightarrow+\infty} \mu e^{-\rho t} H=0
$$

Let define $P=\frac{\mu}{\eta}$ as the relative price of human capital in terms of goods. The costate variables represent the value of one unit of each capital. It follows that $\frac{\dot{P}}{P}=\frac{\dot{\mu}}{\mu}-\frac{\dot{\eta}}{\eta}$.

Using equations (A2) and (A3), we show that the physical capital-human capital ratio in each sector of production is a function only of the relative price. 
It follows that the rental rate of each capital is also a function of the relative price. Assuming there is incomplete specialization in production:

$$
\begin{gathered}
k^{K} \equiv \frac{v K}{u H}=P^{\frac{1}{\alpha-\beta}} \phi \\
k^{H} \equiv \frac{(1-v) K}{(1-u) H}=\frac{1-\alpha}{1-\beta} \frac{\beta}{\alpha} P^{\frac{1}{\alpha-\beta}} \phi \\
r^{K}=\alpha A \phi^{\alpha-1} P^{\frac{\alpha-1}{\alpha-\beta}} \\
r^{H}=(1-\alpha) A \phi^{\alpha} P^{\frac{\alpha}{\alpha-\beta}}
\end{gathered}
$$

where

$$
\phi \equiv\left[\frac{B}{A}\left(\frac{\beta}{\alpha}\right)^{\beta}\left(\frac{1-\alpha}{1-\beta}\right)^{\beta-1}\right]^{\frac{1}{\alpha-\beta}} .
$$

The capital ratio in the consumption and human capital sector are, respectively, $k^{K}$ and $k^{H}$. The rental rate of physical and human capital are represented, respectively, by $r^{K}$ and $r^{H}$.We also define $c=\frac{C}{K}$ and $k=\frac{K}{H}$.

With full employment of factors and the definitions of $k^{K}$ and $k^{H}$ given by the equations (A6) and (A7), there is a relation $\left(u k^{K}+(1-u) k^{H}=k\right)$ that gives the fraction of physical capital used in the goods sector, $u$, as a function of the physical capital-human capital ratio of the economy, $k$, and the relative price, $P$ :

$$
u=\frac{k-k^{H}}{k^{K}-k^{H}}=u(k, P) .
$$

Using these previous equations, the production functions can be expressed as a function of the relative price and the capital ratio:

$$
\begin{gathered}
y^{K} \equiv \frac{Y^{K}}{K}=\frac{1}{\alpha-\beta}\left[(1-\beta) r^{K}-\beta r^{H} \frac{1}{k}\right] \\
y^{H} \equiv \frac{Y^{H}}{H}=\frac{1}{P} \frac{1}{\alpha-\beta}\left[-(1-\alpha) r^{K} k+\alpha r^{H}\right] .
\end{gathered}
$$

The dynamic system is written as:

$$
\begin{gathered}
\frac{\dot{c}}{c}=\frac{\dot{C}}{C}-\frac{\dot{K}}{K}=\frac{1}{\sigma}\left(r^{K}-\delta_{K}-\rho\right)-\left(y^{K}-\delta_{K}-c\right) \\
\frac{\dot{k}}{k}=\frac{\dot{K}}{K}-\frac{\dot{H}}{H}=\left(y^{K}-\delta_{K}-c\right)-\left(y^{H}-\delta_{H}\right)
\end{gathered}
$$




$$
\frac{\dot{P}}{P}=\left(r^{K}-\delta_{K}\right)-\left(\frac{1}{P} r^{H}-\delta_{H}\right)
$$

and takes into account the transversality conditions for $K$ and $H$.

The model has a balanced growth path. In the steady state $\frac{\dot{c}}{c}=\frac{\dot{k}}{k}=\frac{\dot{P}}{P}=0$. Equation (5) gives the steady state value of the relative price $P^{*}$, as the rental rate of physical and human capital depends only on the relative price. We obtain the steady state rental rate of physical capital $\left(r^{K}\right)^{*}$ and human capital $\left(r^{H}\right)^{*}$ using equations (A8) and (A9), respectively. The steady state growth rate is given by $g=\frac{1}{\sigma}\left[\left(r^{K}\right)^{*}-\delta_{K}-\rho\right]>0$. Then we obtain the steady state ratio of capitals $\left(k^{*}\right)$ and consumption over physical capital $\left(c^{*}\right)$ using equations (A14) and (A15).

\section{A.2 The transitional dynamics and the speed of conver- gence}

We assume that the physical sector is more intensive in physical capital $(\alpha>\beta)$ and that there is incomplete specialization in production.

Linearizing the system around the steady state gives:

$$
\left[\begin{array}{c}
\dot{c} \\
\dot{k} \\
\dot{P}
\end{array}\right]=\left[\begin{array}{lll}
a_{11} & a_{12} & a_{13} \\
a_{21} & a_{22} & a_{23} \\
0 & 0 & a_{33}
\end{array}\right] *\left[\begin{array}{l}
c-c^{*} \\
k-k^{*} \\
P-P^{*}
\end{array}\right]
$$

where $a_{i j}$ represents the partial derivative of the equation $i$ with respect to the argument $j$, at the steady state values. $a_{11}=c^{*} ; a_{12}=-\frac{\partial y^{K}}{\partial k} c^{*}<0 ; a_{21}=-k^{*}$; $a_{22}=\left(\frac{\partial y^{K}}{\partial k}-\frac{\partial y^{H}}{\partial k}\right) k^{*}>0$. The expressions of the other coefficients are: $a_{13}=$ $\left(\frac{1}{\sigma} \frac{\partial r^{K}}{\partial P}-\frac{\partial y^{K}}{\partial P}\right) c^{*}$, which has an ambiguous sign; $a_{23}=\left(\frac{\partial y^{K}}{\partial P}-\frac{\partial y^{H}}{\partial P}\right) k^{*}<0$. To this sub-matrix, the trace is $a_{11}+a_{22}>0$ and the determinant is equal to $-\frac{\partial y^{H}}{\partial k} k^{*} c^{*}>0$.

The system has one negative eigenvalue (for the capital ratio $k$ ) and two positive eigenvalues (for the control variables $P$ and $c$ ). Then the dynamics of the system and its speed of convergence can be given by the coefficient $a_{33}$ of 
the equation of the relative price:

$$
a_{33}=-\frac{[(1-\alpha)+\beta]\left(r^{K}\right)^{*}+\beta\left(\delta_{H}-\delta_{K}\right)}{\alpha-\beta} .
$$

Assuming $\delta_{K}=\delta_{H}$, the speed of convergence is given by

$$
\lambda_{C}=\frac{(1-\alpha)+\beta}{\alpha-\beta}\left(r^{K}\right)^{*} .
$$

\section{A.3 The case where the production of human capital is more intensive in physical capital $(\alpha<\beta)$}

We briefly analyze this case. Now $a_{33}>0$ and the negative eigenvalue will be found in a two-by-two matrix: the relative price mechanism is unstable (for a given $k$ ) and the quantities mechanism is stable (for a given relative price).

The trace is

$\operatorname{Tr}=a_{11}+a_{22}=c^{*}+\left(\frac{\partial y^{K}}{\partial k}-\frac{\partial y^{H}}{\partial k}\right) k^{*}$.

And the determinant is given by

Det $=a_{11} a_{22}-a_{12} a_{21}=-c^{*} \frac{\partial y^{H}}{\partial k} k^{*}$.

The negative eigenvalue is equal to

$2 \mu=\operatorname{Tr}-\sqrt{\operatorname{Tr}^{2}-4 \text { Det }}$,

where

$\sqrt{\operatorname{Tr}^{2}-4 \mathrm{Det}}=\left[c^{*}+\left(\frac{\partial y^{K}}{\partial k}+\frac{\partial y^{H}}{\partial k}\right) k^{*}\right]^{2} \underbrace{-4 \frac{\partial y^{K}}{\partial k} \frac{\partial y^{H}}{\partial k} k^{*}}_{>0}$.

In this case the speed of convergence is given by

$$
\lambda_{C}=-\mu=\frac{\partial y^{H}}{\partial k} k^{*}(1+\xi)
$$

with $\xi>0$.

\section{Appendix B The negative eigenvalue associated with the closed economy}

Here we derive the negative eigenvalue associated with the linearization of the system given by equations (16), (17) and (18) in Section 3. 
When human capital is produced only with human capital $(\beta \rightarrow 0)$, the system is reduced to two differential equations on $q$ and $P$. As presented in the text, the system is given by:

$$
\begin{gathered}
\dot{q}=\left(\rho+\delta_{K}+\sigma \frac{\dot{C}}{C}\right) q-r^{K}-(q-1) a-\frac{h}{2}\left(\frac{q-1}{h}\right)^{2} \\
\frac{\dot{P}}{P}=\left(\rho+\delta_{H}-B\right)+\sigma \frac{\dot{C}}{C}
\end{gathered}
$$

where

$$
\frac{\dot{C}}{C}=\left(\frac{q-1}{h}+g\right)+\frac{1}{c}\left(\frac{1}{\alpha} \frac{\alpha-1}{\alpha} r^{K} \frac{\dot{P}}{P}-\frac{q}{h} \dot{q}\right) .
$$

Reorganizing terms leads to

$$
\begin{gathered}
\dot{q}=A_{q}\left[\left(\rho+\delta_{K}\right) q-r^{K}-(q-1) a-\frac{h}{2}\left(\frac{q-1}{h}\right)^{2}+q A_{P} \sigma \frac{q-1}{h}+q g \sigma\right] \\
\frac{\dot{P}}{P}=A_{P}\left[\left(\rho+\delta_{H}-B\right)+\sigma\left(\frac{q-1}{h}+g\right)-\frac{\sigma}{c} \frac{q}{h} \dot{q}\right]
\end{gathered}
$$

where

$$
A_{P}=\frac{1}{1+\frac{\sigma}{c} \frac{1}{\alpha} \frac{1-\alpha}{\alpha} r^{K}}
$$

and

$$
A_{q}=\frac{1}{1+q A_{P} \frac{\sigma}{c} \frac{q}{h}} .
$$

The linearized system can be represented by:

$$
\left[\begin{array}{l}
\dot{q} \\
\dot{P}
\end{array}\right]=\left[\begin{array}{ll}
a_{11} & a_{12} \\
a_{21} & a_{22}
\end{array}\right] *\left[\begin{array}{l}
q-1 \\
P-P^{*}
\end{array}\right]
$$

where

$$
\begin{gathered}
a_{11}=\left[\rho+g(\sigma-1)+A_{P}^{*} \frac{\sigma}{h}\right] A_{q}^{*} \\
a_{12}=\frac{1-\alpha}{\alpha}\left(\frac{r^{K}}{P}\right)^{*} A_{q}^{*} \\
a_{21}=A_{P}^{*} P^{*}\left[\frac{\sigma}{h}-\frac{\sigma}{c^{*}} \frac{1}{h} A_{q}^{*}\left(\rho+g(\sigma-1)+A_{P}^{*} \frac{\sigma}{h}\right)\right] \\
a_{22}=-A_{P}^{*} A_{q}^{*} \frac{\sigma}{c^{*}} \frac{1}{h} \frac{1-\alpha}{\alpha}\left(r^{K}\right)^{*} .
\end{gathered}
$$


By assuming that $\sigma=1$ and $\delta_{K}=\delta_{H}=0$, we have an analytical solution for the speed of convergence of this model.

Now $a=g=B-\rho$ and using equation (8a) one can show that $c^{*}=$ $\frac{\left(r^{K}\right)^{*}}{\alpha}-g=\frac{1-\alpha}{\alpha} B-\rho$. It follows that:

- the trace is equal to $\operatorname{Tr}=\rho$

- the determinant equal to Det $=-\frac{1-\alpha}{\alpha} B \frac{1}{h} A_{P}^{*} A_{q}^{*}$

- and the negative eigenvalue equal to $2 \mu=\rho-\sqrt{\rho^{2}+4 \frac{1-\alpha}{\alpha} B \frac{1}{h} A_{P}^{*} A_{q}^{*}}$.

Let $\lambda_{C(h)}=-\mu$ be the speed of convergence of this closed economy with adjustment costs. By rearranging terms, we can represent the speed of convergence as

$$
2 \lambda_{C(h)}=-\rho+\left[\rho^{2}+4 \frac{1-\alpha}{\alpha} B \Delta\right]^{\frac{1}{2}}
$$

where

$$
\Delta=\frac{1}{h} A_{P}^{*} A_{q}^{*}=\frac{1}{h\left(1+\frac{1}{c^{*}} \frac{1}{\alpha} \frac{1-\alpha}{\alpha} B\right)+\frac{1}{c^{*}}} .
$$

The expression of the speed of convergence corresponds to equation (19) in the text.

The speed of convergence of this closed economy is decreasing in the adjustment costs:

$$
\begin{aligned}
\frac{\partial \lambda_{C(h)}}{\partial h} & =\frac{1}{2}\left[\rho^{2}+4 \frac{1-\alpha}{\alpha} B \Delta\right]^{\frac{1}{2}-1} * \\
& * 4 \frac{1-\alpha}{\alpha} B \Delta^{2}\left(1+\frac{1}{c^{*}} \frac{1}{\alpha} \frac{1-\alpha}{\alpha} B\right)(-1)<0
\end{aligned}
$$

\section{Appendix C The dynamics of foreign bonds}

This appendix derives the dynamics of foreign bonds presented in Section 4 .

We can now analyze the dynamics of consumption and of net foreign bonds. Linearizing equation (24a) we have

$$
\dot{c}=-\frac{c^{*}}{h}(q-1)=-\frac{c^{*}}{h} \Gamma\left(k_{0}-k^{*}\right) e^{-\lambda_{O} t}
$$

and the solution of this differential equation is given by

$$
\left(c-c^{*}\right)=\frac{-\frac{c^{*}}{h} \Gamma}{-\lambda_{O}}\left(k_{0}-k^{*}\right) e^{-\lambda_{O} t} .
$$


By linearizing equation (24b) and by taking into account the previous equations:

$$
\dot{d}=\left(r^{*}-g\right)\left(d-d^{*}\right)+\Lambda\left(k-k^{*}\right)
$$

with

$$
\Lambda=\left[\left(y_{P}^{K} \Pi+y_{k}^{K}\right)+\frac{\frac{c^{*}}{h} \Gamma}{-\lambda_{O}}-\left(\frac{d^{*}+1}{h}\right) \Gamma\right]
$$

and

$$
\Gamma=\frac{-\left(\lambda_{O}+a_{11}\right)}{\frac{k^{*}}{h}-\frac{a_{13}}{a_{23}}\left(r^{*}-g+\lambda_{O}\right)} \text { and } \Pi=\frac{-\left(r^{*}-g+\lambda_{O}\right)}{a_{23}} \Gamma .
$$

The signs of the expressions in $\Lambda$ are: $y_{P}^{K}<0 ; y_{k}^{K}>0 ; \Pi>0 ; \Gamma<0$. These expressions are related to the solution of the system of differential equations, $k$, $q$ and $P$. It follows that the ambiguity of the sign of $\Lambda$ comes from $y_{P}^{K}$ being negative, as all other expressions are positive.

The solution of this differential equation is given by:

$$
\begin{aligned}
\left(d-d^{*}\right) & =\frac{\Lambda}{-\lambda_{O}-\left(r^{*}-g\right)}\left(k_{0}-k^{*}\right) e^{-\lambda_{O} t}+ \\
& +\left[d_{0}-d^{*}-\frac{\Lambda}{-\lambda_{O}-\left(r^{*}-g\right)}\left(k_{0}-k^{*}\right)\right] e^{\left(r^{*}-g\right) t}
\end{aligned}
$$

with the equation in brackets set equal to zero to observe the transversality condition of net foreign bonds, $D$. We have then

$$
\left(d-d^{*}\right)=\frac{\Lambda}{-\lambda_{O}-\left(r^{*}-g\right)}\left(k_{0}-k^{*}\right) e^{-\lambda_{O} t} .
$$

This is equation (26) presented in the text.

\section{References}

Abel, A. and Blanchard, O. (1983), 'An intertemporal model of saving and investment', Econometrica 51, 675-692.

Acemoglu, D. and Ventura, J. (2002), 'The world income distribution', Quartely Journal of Economics 117, 659-694.

Barro, R. J., Mankiw, N. G. and Sala-i-Martin, X. (1995), 'Capital mobility in neoclassical models of growth', American Economic Review 85(1), 103-115. 
Barro, R. and Sala-i-Martin, X. (1995), Economic Growth, New York: McGrawHill.

Bond, E., Wang, P. and Yip, C. (1996), 'A general two-sector model of endogenous growth with human and physical capital: Balanced growth and transitional dynamics', Journal of Economic Theory 68, 149-173.

Brock, P. and Turnovsky, S. (1994), 'The dependent economy model with both traded and non traded capital goods', Review of International Economics 2, 306-325.

Bruno, M. (1976), 'The two-sector open economy and the real exchange rate', American Economic Review 66(4), 566-577.

Farmer, R. and Lahiri, A. (2002), Economic growth in an interdependent world economy. CEPR Discussion Paper N. 3250.

Grossman, G. M. and Helpman, E. (1991), Innovation and Growth in the Global Economy, MIT Press.

Howitt, P. (2000), 'Endogenous growth and cross-country income differences', American Economic Review 90, 829-846.

King, R. and Rebelo, S. (1993), 'Transitional dynamics and economic growth in the neoclassical model', American Economic Review 83, 908-931.

Lane, P. and Milesi-Ferretti, G. M. (2001), 'The external wealth of nations: Measures of foreign assets and liabilities for industrial and developing nations', Journal of International Economics 55, 263-294.

Lucas, R. (1988), 'On the mechanics of economic development', Journal of Monetary Economics 22, 3-42.

Mulligan, C. B. and Sala-i-Martin, X. (1993), 'Transitional dynamics in twosector models of endogenous growth', Quartely Journal of Economics 108(3), 737-773. 
Obstfeld, M. (1994), 'Risk-taking, global diversification and growth', American Economic Review 85, 1310-1329.

Obstfeld, M. and Rogoff, K. (1996), Foundations of International Macroeconomics, Cambridge MA: MIT Press.

Ortigueira, S. and Santos, M. (1997), 'On the speed of convergence in endogenous growth models', American Economic Review 87, 383-399.

Prasad, E., Rogoff, K., Wei, S.-J. and Kose, M. A. (2003), Effects of Financial Globalization on Developing Countries: Some Empirical Evidence, International Monetary Fund Occasional Paper 220, Washington DC: International Monetary Fund.

Rebelo, S. (1991), 'Long-run policy analysis and long-run growth', Journal of Political Economy 99(3), 500-521.

Summers, L. (1981), 'Taxation and corporate investment: A $q$-theory approach', Brookings Papers on Economic Activity 1(1), 67-127.

Turnovsky, S. (1996), 'Endogenous growth in a dependent economy with traded and nontraded capital', Review of International Economics 4, 300-321.

Ventura, J. (1997), 'Growth and interdependence', Quartely Journal of Economics 112, 57-84. 


\section{Appendix Table 1:}

Financial openness and convergence

\begin{tabular}{lcc}
\hline \hline & $\begin{array}{c}(\mathrm{i}) \\
D Y 0080 \\
\text { OECD }\end{array}$ & $\begin{array}{c}(\mathrm{ii}) \\
D Y \text { OE } 8060 \\
\text { OEC }\end{array}$ \\
\cline { 2 - 3 }$Y_{0}$ & $\begin{array}{c}-0.388 \\
(-1.932)\end{array}$ & $\begin{array}{c}-0.513 \\
(-6.443)\end{array}$ \\
$\bar{R}^{2}$ & 0.27 & 0.72 \\
N. Obs. & 20 & 20
\end{tabular}

OLS regressions using $\overline{\overline{\text { robust standard errors. } t \text {-statistics are in parenthesis. Dependent }}}$ variable: real per capita GDP growth $(D Y) . Y_{0}$ is the logarithm of initial real per capita GDP. All regressions include a constant (not reported). The regressions (i) and (ii) use the Penn World Table (version 6.1). This database is available at: http://pwt.econ.upenn.edu/. The countries in the sample OECD are the following: Australia, Austria, Belgium, Canada, Denmark, Finland, France, Greece, Ireland, Italy, Japan, Netherland, Norway, New Zealand, Portugal, Spain, Sweden, Switzerland, United Kingdon and USA. 